\title{
Laser Ablation Inductively Coupled Plasma Mass Spectrometry of Pressed Pellet Surrogates for Pu Materials Disposition
}

Oleg V. Borisov ${ }^{\mathrm{a}}$, Christopher J. Bannochie ${ }^{\mathrm{b}}$, and Richard E. Russo ${ }^{\mathrm{a}}$

a Lawrence Berkeley National Laboratory, Berkeley, CA 94720.

b Westinghouse Savannah River Company, Aiken, SC 29808.

Lawrence Livermore National Laboratory, Livermore, CA 94550.

\begin{abstract}
Successful $\mathrm{Pu}$ disposition by immobilization in glass or ceramic form requires accurate and precise knowledge of impurity amounts. Analysis of $\mathrm{Pu}$ material by conventional liquid nebulization requires dissolution, which is difficult due to a refractory nature of the samples. Laser ablation is a suitable sampling technique for direct analysis of solids. This paper demonstrates the procedures that were established for $\mathrm{PuO}_{2}$ analysis using laser ablation ICP-MS. Pressed pellets prepared from $\mathrm{CeO}_{2}$ were used to simulate $\mathrm{PuO}_{2}$. Effects of laser conditions, sample preparation, and matrix composition, specifically mass of a matrix element and color, on the analyses of $\mathrm{CeO}_{2}, \mathrm{Bi}_{2} \mathrm{O}_{3}$, and $\mathrm{PtO}_{2}$ based pressed pellets was examined. Influence of mixing/grinding time on particle sizes, sample homogeneity, and ablation efficiency was investigated. Laser conditions that produce stoichiometric sampling were examined.
\end{abstract}

Index Headings: Laser ablation, Solid sample introduction, ICP-MS, pressed pellets 


\section{Introduction}

The goal of the Plutonium Immobilization Program (PIP), conducted on behalf of the DOE Office of Fissile Material Disposition (NN 60) is to immobilize 18 to 50 metric tons (MT) of U.S. surplus weapons-usable plutonium materials, in a manner which meets the "spent fuel" standard, and that is compatible with disposal in a geologic repository [1]. The Material Characterization task of the PIP must provide process control for impure oxide washing operations, identify unknown or unsuspected elemental constituents in oxide streams, and provide data for "smart" oxide blending operations during ceramification to reduce re-blend requirements. A critical part of this effort is to quantify elemental impurity levels in calcined plutonium oxide feed materials. In general the analytical method needs to determine the elemental constituents in plutonium oxide feed with sufficient accuracy to flag problematic levels of impurities. This analysis entails the measurement of a variety of elements, including low atomic number $(Z)$ elements, in a heavy element matrix. The selected method must minimize sample preparation, waste generation, operator/technician radiation exposure, and delays to plant processing operations. Additionally, it is important to rapidly identify materials requiring further processing or blending.

The purpose of this research was to access the effectiveness of laser ablation inductively coupled mass spectrometry (LA/ICP-MS) for this application, using heavy metal oxides as surrogates for the plutonium oxide samples. Laser ablation has been established as a viable technology for direct solid sample chemical analysis [2-4]. The technology offers many advantages over traditional sample digestion and liquid nebulization. For example, only a very small quantity of sample is required for the analysis with very little sample preparation. Therefore, there is minimal sample handling required by the analyst, minimizing the possibility of hazardous exposure and contamination. In addition, there is no additional waste generated since acid solutions are not required for digestion. Finally, because the sample is introduced into the ICP as a dry vapor, interferences due to oxides are reduced.

For quantitative analysis, standards must be developed and the standards must be a good representation of the unknown sample. The basis of this work was to evaluate 
mixed oxide pressed-powder samples, which are characteristic of calcined plutonium oxide feed materials. Analyses of pressed pellets have been investigated [5-11]. Pressed pellets are made to enable the ablation of otherwise loosely consolidated materials such as powders. Inhomogeneous samples are often ground and pressed into pellets so that they can be more representatively sampled. Analysis of pressed pellets offers an advantage that internal standard(s) can be easily added and matrix-matched standards can be generated. Addition of a binder, typically a polymer compound, improves sample handling and laser ablation properties $[5,10]$.

A series of pressed-pellet standards were made with and without binders, and the laser conditions established for optimum characterization of the impurity components. Laser beam properties affect accuracy and precision $[2,8]$. The experiments addressed the impact of sample preparation procedures, including binder composition, Teflon or poly(ethylene glycol), and the mixing ratio of the binder with the metal oxide. A series of standards with different concentrations of elements was prepared for calibration. Matrix effects resulting from matrix color $\left(\mathrm{PtO}_{2}\right)$ and mass $\left(\mathrm{Bi}_{2} \mathrm{O}_{3}\right)$ were also addressed.

\section{Experimental}

\section{Materials}

Pure $\left(99.99 \%\right.$ or better) metal oxides and salts $\left(\mathrm{Al}_{2} \mathrm{O}_{3}, \mathrm{Bi}_{2} \mathrm{O}_{3}, \mathrm{~B}_{2} \mathrm{O}_{3}, \mathrm{CaF}_{2}, \mathrm{CaO}\right.$, $\mathrm{CeO}_{2}, \mathrm{Cr}_{2} \mathrm{O}_{3}, \mathrm{Fe}_{2} \mathrm{O}_{3}, \mathrm{Ga}_{2} \mathrm{O}_{3}, \mathrm{In}_{2} \mathrm{O}_{3}, \mathrm{KCl}, \mathrm{La}_{2} \mathrm{O}_{3}, \mathrm{MgO}, \mathrm{MoO}_{3}, \mathrm{NaCl}, \mathrm{Nd}_{2} \mathrm{O}_{3}, \mathrm{NiO}, \mathrm{PbO}$, $\mathrm{PtO}_{2} \cdot \mathrm{H}_{2} \mathrm{O}, \mathrm{SiO}_{2}, \mathrm{SnO}_{2}, \mathrm{Ta}_{2} \mathrm{O}_{5}, \mathrm{WO}_{3}$, and $\mathrm{ZnO}$ ) were obtained from Aldrich Chemical Company and used without further purification. Additionally, the following binder

reagents were obtained from Aldrich: polytetrafluoroethylene (Teflon ${ }^{\circledR}$ ), 12-micron powder and poly(ethylene glycol) (PEG). All reagents were stored in a vacuum dessicator when not in use.

Sample Preparation

Pellets were pressed with a Powder Testing Center Model PTC-03DT fitted with a 3/8" diameter stainless steel die, and each pellet was pressed utilizing $1 \mathrm{~g}$ of sample oxide mixture at 20,000 psi (unless specified otherwise). 
Pellets Prepared without a Binder

Mixed oxide pellets prepared without binder were wet ball milled and dried for 24 hours at $105^{\circ} \mathrm{C}$ or dry attritor milled using large-scale hardware prior to pressing. The metal oxides were standard ACS reagent grade materials (rather than the higher purity materials employed in the remainder of the study), used without further purification. The pellet formulations were based on ceramification product formulations, and therefore varied from those developed for the remainder of this study. The composition consisted of the following materials: $\mathrm{Al}_{2} \mathrm{O}_{3}, \mathrm{H}_{3} \mathrm{BO}_{3}, \mathrm{BaO}, \mathrm{CaCl}_{2}, \mathrm{CeO}_{2}, \mathrm{CuSO}_{4}, \mathrm{CaF}_{2}, \mathrm{Fe}_{2} \mathrm{O}_{3}$, $\mathrm{Ga}_{2} \mathrm{O}_{3}, \mathrm{KOH}, \mathrm{La}_{2} \mathrm{O}_{3}, \mathrm{MgO}, \mathrm{MoO}_{3}, \mathrm{NaOH}, \mathrm{Nd}_{2} \mathrm{O}_{3}, \mathrm{NiO},\left(\mathrm{NH}_{4}\right)_{2} \mathrm{HPO}_{4}, \mathrm{PbO}, \mathrm{SiO}_{2}, \mathrm{SnO}_{2}$, $\mathrm{Ta}_{2} \mathrm{O}_{5}, \mathrm{WO}_{3}$, and $\mathrm{ZnO}$. These pellets were pressed with a 3/4" die from $6 \mathrm{~g}$ of powder.

Pellets Prepared with Teflon ${ }^{\circledR}$ and PEG for Binder Evaluation.

$\mathrm{CeO}_{2}, \mathrm{In}_{2} \mathrm{O}_{3}$, and binder were separately weighed with an analytical balance directly into the mixing vessels. A $15 \%$ binder concentration was used with mixing intervals of 5-, 10-, and 15-minutes. Mixing was performed with a Retch Wigglebug mill in 5-mL agate-lined stainless steel mixing/milling vessels paired with two 7-mm agate mixing/milling balls each. The Teflon ${ }^{\circledR}$ binder samples were mixed at a frequency of $1 / 30^{\text {th }}$ second, while those samples containing poly(ethylene glycol) are mixed at a frequency of $1 / 20^{\text {th }}$ second. All pellets were pressed at 20,000 psi except for the PEG blank, which was pressed at 2,000 psi - this binder did not permit greater pressures when uncombined with other materials. As the concentration of PEG increased, the pellet size (thickness) increased accordingly and the density decreased.

\section{Preparation of Standards}

A series of standards (pellets) containing a variety of metal oxides were formulated with $\mathrm{CeO}_{2}$ as a surrogate for $\mathrm{PuO}_{2}$. The sum of the remaining metal oxides were bracketed around a total nominal concentration of $34 \%(\mathrm{w} / \mathrm{w})$ to provide $-75 \%$, $37.5 \%,+37.5 \%$, and $+75 \%$ of the nominal concentration. Therefore the $\mathrm{CeO}_{2}$ concentration varied from 75 to $25 \%(\mathrm{w} / \mathrm{w})$ across the series of five pellets. For these standards, the mixed metal oxides (other than $\mathrm{CeO}_{2}$ ) were prepared by placing the weighed amount of each oxide into a $25 \mathrm{~mL}$ agate mixing/milling vessel with seven 12- 
mm agate mixing/milling balls. The combined oxides were then processed on a Fritsch Planetary Micro-Mill Model P7. The $\mathrm{In}_{2} \mathrm{O}_{3}$ internal standard and Teflon ${ }^{\circledR}$ binder were mixed separately. The planetary mill was operated at $500 \mathrm{rpm}$ with four repetitions of 15-minutes and one repetition of 30-minutes. The final pellet formulation was then prepared by combining the metal oxide mixture, $\mathrm{In}_{2} \mathrm{O}_{3} /$ Teflon ${ }^{\circledR}$ mixture, and the $\mathrm{CeO}_{2}$ into a $5 \mathrm{~mL}$ agate-lined stainless steel mixing/milling vessel as described above; however, the mixing interval was increased to 50-minutes.

Three additional pellets were prepared by substituting the $\mathrm{CeO}_{2}$ at the nominal concentration of $34 \%(\mathrm{w} / \mathrm{w})$ for $\mathrm{Bi}_{2} \mathrm{O}_{3}, \mathrm{MgO}$, or $\mathrm{PtO}_{2}$. Additional mixing time (20 minutes) was required to prevent layering of the final pellet mixture when $\mathrm{MgO}$ was substituted into the base formulation.

\section{Laser Ablation ICP-MS System}

The experimental system included a PQ3 ICP-MS (VG Elemental), a Nd:YAG laser (New Wave Research) frequency quadrupled $(266 \mathrm{~nm})$ with a 6-ns pulse width, and an ablation cell developed in-house $[2,4]$. The laser was operated at $10 \mathrm{~Hz}$ repetition rate. A plano-convex lens with nominal focal length of $20 \mathrm{~cm}$ was used for focusing the laser beam onto a sample surface. Alternatively, a New Wave-Merchantek LUV266 laser ablation system was used in raster-mode experiments. In both cases, laser ablated mass was entrained into an Ar gas flow at a flow rate of $0.9 \mathrm{~L} / \mathrm{min}$ and carried to the ICP torch via $1.4 \mathrm{~m}$ long and $0.41 \mathrm{~cm}$ (i.d.) wide polyethylene tubing. The ICP-MS was operated at a forward RF power of $1350 \mathrm{~W}$ and gas flow rates of 14 and $1.0 \mathrm{~L} / \mathrm{min}$ respectively for plasma and auxiliary flows.

A white-light interferometric microscope (New View 200, Zygo Corporation) was used to examine crater parameters, such as diameter, depth, and volume. This microscope can simultaneous measure a surface area of $500 \times 500 \mu \mathrm{m}^{2}$ and a depth of 100 $\mu \mathrm{m}$. Measurements of crater volume provide the amount of ablated mass used to compensate for changes in the mass ablation efficiency, and thereby improve precision. 


\section{Results and Discussion}

\section{Laser ablation of pressed pellets prepared without binder}

The initial studies were performed on the set of samples prepared without a binder. Pressed pellets prepared without binder were fragile, complicating their mounting onto the vertical ablation stage. Laser ablation of these pellets produced excessively large particulates $(>10-50 \mu \mathrm{m})$ that were scattered around the crater and deposited in the chamber. As a result of poor laser ablation characteristics of these samples, the ICP-MS signal had poor stability, and was composed of large spikes measured during the time-profile. However, despite these difficulties, some preliminary analytical measurements were made. The effect of grinding time on laser sampling was examined. Pellets prepared using 4 hours of grinding time were composed of smaller particle-sizes compared to the ones prepared using 1 hour of grinding time. The smaller particle size distribution due to longer grinding time did not improve the laser ablation characteristics of these pressed pellets. In contrast, increased grinding time resulted in increased contamination with elements from grinding vessels and mixing balls.

Semi-quantitative analysis was performed on these samples. An ICP-MS response curve was generated by ablating NIST 610 glass standard to estimate relative intensities for different elements. The signal intensity of ${ }^{136} \mathrm{Ce}$ isotope was used as an internal standard during ablation of the pressed pellets, and the concentrations for the elements of interest were determined from the response curve (Table 1). Data provided by two other laboratories with sample dissolution and ICP-AES/MS analyses are given for comparison, but should not be interpreted as reference values. The liquid nebulization data may be prone to errors as un-dissolved particles left in a solution after the digestion procedure were reported, causing poor recoveries for some elements. The digestion procedure was not optimized for complete dissolution of the sample material. Despite poor laser ablation behavior of these pellets, reasonable agreement between the sets of data was obtained for several elements.

\section{Laser ablation of Ce - In oxide pressed pellets prepared with binder}

A binder was used to improve sample stability and laser ablation behavior. Two binders, poly(ethylene glycol) and Teflon ${ }^{\circledR}$ were tested. Pellets were prepared by mixing 
specific amounts of $\mathrm{CeO}_{2}$ and $\mathrm{In}_{2} \mathrm{O}_{3}$ powders with 15,30 , and $45 \%(\mathrm{w} / \mathrm{w})$ of each binder. The $\mathrm{In} / \mathrm{Ce}$ elemental ratio in all samples was maintained at 0.005 . The measured dependence of ablated mass on the amount of binder is shown in Fig. 1. The amount of ablated mass decreased with the amount of binder which may be due to the differences in density of the pellets; density decreased as the amount of binder increased. For Teflon ${ }^{\circledR}$ and poly(ethylene glycol) pellets, the density decreased respectively by 21 and $34 \%$ when binder concentration was increased from 15 to $45 \%$. Pellets with higher density generally had a higher ablation rate. The optical properties of the pellets also affected the amount of ablated mass. Increasing amounts of Ce oxide produced darker color pellets, which also may explain the decrease in the amount of ablated mass for samples with a higher percentage of binder. Smaller amounts of mass were ablated from Teflon ${ }^{\circledR}$ pellets, in the range of $0.5-1.2 \mathrm{ng}$ per average laser pulse. As observed for both In and $\mathrm{Ce}$, the signal intensity decreased by at least an order of magnitude when the binder concentration was increased from 15 to $45 \%$.

Decreasing the mixing time from 15 to $5 \mathrm{~min}$ did not significantly degrade the signal intensity; different mixing times were tested to insure good homogeneity of the samples. RSD values for a series of five ablation experiments on a fresh randomly selected sample surface were in the range of $5-10 \%$.

The effect of irradiance on the ablation rate and ICP-MS signal time profiles was investigated by ablating a sample with $15 \%$ Teflon ${ }^{\circledR}$ binder. The ICP-MS signal intensity increased with irradiance (Fig. 2). Signal intensity stabilized much faster during repetitive ablation when the irradiance was increased from 0.006 to $0.016 \mathrm{GW} \mathrm{cm}$. Time-profiles for both ${ }^{138} \mathrm{Ce}$ and ${ }^{115} \mathrm{In}$ were similar. In contrast, when the irradiance was increased above $0.2 \mathrm{GW} \mathrm{cm}{ }^{-2}$, the ${ }^{138} \mathrm{Ce}$ signal intensity continuously decreased. The ${ }^{115}$ In signal becomes unstable due to grain effects. At this irradiance a crater develops much faster compared to those at lower irradiances. The formation of a high aspect ratio crater can decrease the ablation rate and therefore signal intensity [12, 13]. Any local inhomogeniety in the elemental distribution becomes significant. Because the $\operatorname{In}_{2} \mathrm{O}_{3}$ concentration in the samples was much less than $\mathrm{CeO}_{2}(\mathrm{In} / \mathrm{Ce}$ ratio in the samples was about 0.005$)$, the In signal is affected to a greater extent. The laser beam spot diameter 
must be larger than the grain sizes. For these samples, the laser irradiance of $0.015 \mathrm{GW}$ $\mathrm{cm}^{-2}$ provided an appropriate spot diameter and good sampling precision.

Accuracy of sampling was determined by examining $\mathrm{In} / \mathrm{Ce}$ elemental ratios. Figure 3 shows the time profiles of the ratio at different irradiances. The "expected" ratio based on sample composition and corrected for mass bias also is shown Fig. 3a. Increasing the irradiance from 0.006 to $0.016 \mathrm{GW} \mathrm{cm}^{-2}$ improved the sampling reproducibility. At this irradiance, the ratio was close to the expected value after about $60 \mathrm{~s}$ of repetitive ablation. In contrast, at irradiances above $0.2 \mathrm{GW} \mathrm{cm}{ }^{-2}$, the ratio was noisy due to the signal intensity fluctuations for In (cf Fig. 2b). The effect of irradiance on the $\mathrm{In} / \mathrm{Ce}$ ratio is shown in Fig. $3 \mathrm{~b}$ for repetitive ablation of the Teflon ${ }^{\circledR}$ and poly(ethylene glycol) pellets. Irradiance in the range of $0.01-0.1 \mathrm{GW} \mathrm{cm}^{-2}$ produced stoichiometric ablation. For irradiance larger than approximately $0.3 \mathrm{GW} \mathrm{cm}^{-2}$ stoichiometry was poor primarily due to fast crater formation. Fractionation increases with the crater aspect ratio (depth/diameter).

These data demonstrate that laser ablation accuracy and precision for pressed pellets depends on laser operating conditions; the irradiance must be carefully selected for optimum conditions. The irradiance must be high enough to provide good sensitivity and low enough so that the ablation rate is not too fast, and the beam spot size must be larger than the grain size.

\section{Laser ablation conditions for mixed-oxide pressed pellets with Teflon ${ }^{\circledR}$ binder}

Samples prepared with the Teflon ${ }^{\circledR}$ binder were used in the remainder of the experiments. This choice was based on the fact that density of the Teflon ${ }^{\circledR}$ pellets was less dependent on the amount of binder, compared to poly(ethylene glycol) pellets. Laser ablation of pressed pellets, prepared by mixing 21 oxides with Teflon ${ }^{\circledR}$ binder, was examined as a function of irradiance to select conditions for accurate and precise analysis. The ${ }^{136} \mathrm{Ce}$ ICP-MS signal intensity was integrated over $120 \mathrm{~s}$ of repetitive ablation, and normalized to laser beam area. These data versus irradiance for the $\mathrm{CeO}_{2}$ pellet with nominal composition are shown in Fig. 4a. The signal intensity linearly increased with irradiance, until approximately $0.2-0.3 \mathrm{GW} \mathrm{cm}^{-2}$ at which point the signal intensity rolled-off. Further increases in irradiance did not significantly influence 
signal levels. The occurrence of roll-off is characteristic of laser ablation with ns pulses and was reported for a variety of samples independent of their composition and homogeneity [2].

The effect of elemental fractionation was studied by measuring $\mathrm{Pb} / \mathrm{Ce}$ ratios (Fig. 4a). $\mathrm{Pb}$ and $\mathrm{Ce}$ were chosen due to large differences in melting properties of the oxides $\left(886{ }^{\circ} \mathrm{C}\right.$ for $\mathrm{PbO}$ and $2600{ }^{\circ} \mathrm{C}$ for $\mathrm{CeO}_{2}$ ). At irradiances lower than approximately 0.06 $\mathrm{GW} \mathrm{cm}{ }^{-2}$ the ratio linearly decreased with increasing irradiance. Thermal vaporization is a possible mechanism responsible for the measured ratio at low irradiances [2]. For irradiances in the range $0.06-0.1 \mathrm{GW} \mathrm{cm}^{-2}$ the ratio closely matched the stoichiometric composition. For irradiances above $0.2 \mathrm{GW} \mathrm{cm}$, the ratio increased above the stoichiometric value, possibly due to the effect of plasma radiation on the sampling process or the formation of a deep crater $[12,13]$.

The ICP-MS precision with laser ablation sampling of pressed pellets was also found to be a function of laser irradiance (Fig. 4b). RSD's were calculated using $\mathrm{Ce}$ signal intensities measured over 120 seconds of repetitive laser ablation, excluding the signal for the first 10 seconds. Such a long integration time is indicative of signal stability during repetitive pulsing. For low irradiances, the ICP-MS signal levels were low and the precision was poor. Increasing the ICP-MS signal by using irradiances of $0.1-0.2 \mathrm{GW} \mathrm{cm}{ }^{-2}$ improved RSD's to below $10 \%$. Further increases in irradiance above $0.2 \mathrm{GW} \mathrm{cm}^{-2}$ did not improve precision. Instead, due to the rapid formation of the ablation crater and a beam diameter on the order of the grain sizes in the pellets, precision was poor during ablation at irradiances above $0.2 \mathrm{GW} \mathrm{cm}^{-2}$. Based on these studies, laser ablation conditions that provided accurate and precise sampling for these samples were established. The optimum laser irradiance was $0.1 \mathrm{GW} \mathrm{cm}$, corresponding to a beam diameter of $200 \mu \mathrm{m}$ and $200 \mu \mathrm{J}$ of energy per pulse.

\section{Quantitative analysis of mixed-oxide pressed pellets}

The effect of sample composition on laser ablation behavior of pressed pellets was studied by measuring In signal intensity as a function of the amount of ablated mass, after $30 \mathrm{~s}$ of repetitive sampling (Fig. 5). Indium oxide was added to all of the samples as an internal standard in the amount of $1.9 \%(\mathrm{w} / \mathrm{w})$. The composition of the matrix 
influenced the quantity of mass ablated; $\mathrm{CeO}_{2}, \mathrm{Bi}_{2} \mathrm{O}_{3}, \mathrm{PtO}_{2}$, and $\mathrm{MgO}$ pellets were examined. The amount of ablated mass decreased as $\mathrm{CeO}_{2}$ matrix amounts decreased in the range 75 to $25 \%(\mathrm{w} / \mathrm{w})$. The chemical composition of the matrix oxide affected the quantity of ablated mass because of changes in the sample density and optical properties. When $\mathrm{CeO}_{2}$ was replaced with $\mathrm{Bi}, \mathrm{Pt}$, or $\mathrm{Mg}$ oxides, these properties were changed and thus the amount of ablated mass changed.

Two calibration procedures were tested. For the first approach, laser ablation was performed at a single sample location. In the second case, the sample stage was translated using a zigzag pattern, covering a $1.5^{*} 10^{5} \mu \mathrm{m}^{2}$ area on the sample surface. The overlap between pulses was minimized by selecting a $200 \mu \mathrm{m}$ distance between the raster patterns, a translation speed of $100 \mu \mathrm{m}$ per s, and a total of 15 passes. This raster pattern also was selected to minimize contamination. In both cases, the laser beam spot on the sample surface was $200 \mu \mathrm{m}$ in diameter, the laser energy was $200 \mu \mathrm{J}$, and the laser was operated at a repetition rate of $10 \mathrm{~Hz}$. Data were acquired for $30 \mathrm{~s}$ after $120 \mathrm{~s}$ of a pre-ablation time.

Signal intensities for the ${ }^{115} \mathrm{In}$ internal standard in the set of $\mathrm{CeO}_{2}$ pressed pellets are compared in Fig. 6 for single spot and raster mode ablation. The In oxide concentration in these samples was constant. The ${ }^{115}$ In signal intensity increased with $\mathrm{CeO}_{2}$ concentration in the samples when sampling from a single spot. In contrast, the internal standard signal intensity did not change significantly during rastering. In general, the raster mode produced higher signal intensities compared to repetitive ablation at a single spot. Also, single spot ablation produced poor calibration not suitable for quantitative analysis; with no internal standardization, non-linearity is evident (Fig. 7a). Greater differences were measured when the matrix was replaced with $\mathrm{Bi}, \mathrm{Pt}$, or $\mathrm{Mg}$ oxides, clearly illustrating the effects that the matrix has on the ablation process. Matrix effects can be minimized by using raster mode, as shown in Fig. 6 and 7b. This is true for the $\mathrm{CeO}_{2}$ matrix in the concentration range of 25 to $75 \%$. Although raster mode ablation did not completely eliminate matrix effects when the sample matrix composition was changed from $\mathrm{CeO}_{2}$ to $\mathrm{Bi}, \mathrm{Pt}$, and $\mathrm{Mg}$ oxides, their significance was greatly reduced. These data shows that the raster mode can compensate for "small" changes in composition, such as concentration variations of a matrix $\left(\mathrm{CeO}_{2}\right.$ in the range of 25 to 
$75 \%$ ), compared to ablation at a single spot. However, when the matrix oxide changed, in the case of $\mathrm{Bi}, \mathrm{Pt}$, and $\mathrm{Mg}$ oxides, neither rastering nor single spot ablation could completely compensate for these changes.

Internal standardization procedures are needed to compensate for a broad spectrum of matrix properties. As an example, internal standardization was employed to correct calibration non-linearity during single spot ablation (similar dependences were generated for raster mode, data not shown). When ${ }^{208} \mathrm{~Pb}$ signal intensity was normalized to the ${ }^{113}$ In intensity, a linear calibration curve was generated (Fig. 7c). "Matrix effects" for $\mathrm{Bi}, \mathrm{Pt}$, and $\mathrm{Mg}$ matrix oxide samples were corrected using internal standardization. The quantitative analysis performed for several pressed pellets using In as an internal standard and the $\mathrm{CeO}_{2}$ standards for calibration are given in Table 2. Good accuracy was achieved in most cases; deviations from the expected values were greatest for $\mathrm{Bi}, \mathrm{Pt}$, and $\mathrm{Mg}$ oxide pellets. As evident from these preliminary data, some differences in ablation behavior of samples with different matrix composition exist (for several elements) and cannot be easily compensated for by ablation in a raster mode or internal standardization. Further investigation of the differences in elemental behavior due to the matrix composition is needed. Also, this behavior could be related to sample homogeneity. The internal standard, $\operatorname{In}_{2} \mathrm{O}_{3}$, was mixed with a binder to achieve a uniform concentration throughout the samples. Analyte oxides were mixed separately. It is possible that In was inhomogeneously distributed in these samples.

\section{Conclusion}

Laser ablation ICP-MS analysis has been shown to be a successful method for the quantitative characterization of mixed metal oxide pressed pellets. Laser irradiance impacted both the accuracy and precision and must be sufficiently high to provide good sensitivity but low enough to prevent too high of an ablation rate. Additionally, the beam spot size must be larger than the grain size. The optimum laser irradiance was $0.1 \mathrm{GW}$ $\mathrm{cm}-2$, corresponding to a beam diameter of $200 \mu \mathrm{m}$ and $200 \mathrm{~mJ}$ of energy per pulse.

In cases where composition of the matrix changes, single spot ablation could not produce satisfactory standardization curves. In contrast, the raster mode ablation was more successful at minimizing matrix effects, when the concentration of a matrix element 
in the calibration standards and samples was different. For samples with different matrix chemical composition, the raster mode alone did not compensate for changes in optical properties of the samples. Internal standardization was essential for obtaining accurate results. When internal standardization was applied, matrix effects were significantly reduced facilitating analytical determinations.

\section{Acknowledgement}

This work was supported at Lawrence Berkeley National Lab by the Environmental Management Science Program, funded jointly by the Assistant Secretary for Environmental Management and by the Director, Office of Energy Research, of the U.S. Department of Energy, under Contract No. DE-AC03-76SF00098 and by the Office of Fissile Material Disposition (NN-60) under the auspices of the U. S. Department of Energy by Lawrence Livermore National Laboratory under Contract No. W-7405-ENG48. 


\section{References}

1) "Integrated Development and Testing Plan for the Plutonium Immobilization Project", Lawrence Livermore National Laboratory, Westinghouse Savannah River Company, Argonne National Laboratory, and Pacific Northwest National Laboratory, March 27, 2000, UCRL-ID-131608, Rev 3 PIP-00-035.

2) R. E. Russo, X.L. Mao, O.V. Borisov, and H.C. Liu, Laser Ablation in Atomic Spectrometry, "Encyclopedia of Analytical Chemistry: Instrumentation and Applications, John Wiley \& Sons, July 2000.

3) H.C. Liu, O.V. Borisov, X.L. Mao, S. Shuttleworth, and R.E. Russo, Applied Spectroscopy, V54(N10), 1435-1442 (2000).

4) O.V. Borisov, X.L. Mao, A. Fernandez, M. Caetano, and R.E. Russo, Spectrochimica Acta B, V54(N9), 1351-1365 (1999).

5) A.A. van Heuzen and J.B.W. Morsink, Spectrochim. Acta, 46B, 1819-1828 (1991).

6) A. Raith and R.C. Hutton, Fresenius' J. Anal. Chem., 350, 242-246 (1994).

7) W.T. Perkins, N.J.G. Pearce and T.E. Jeffries, Geochimica et Cosmochimica Acta, 57, 475-482 (1993).

8) W.T. Perkins, R. Fuge and N.J.G. Pearce, J. Anal. At. Spectrom., 6, 445-449 (1991).

9) M. Motelica-Heino, O.F.X. Donard and J.M. Mermet, J. Anal. At. Spectrom., 14, 675682 (1999).

10) E.R. Denoyer, J. Anal. At. Spectrom., 7, 1187-1193 (1992).

11) S.A. Baker, M. Bi, R.Q. Aucelio, B.W. Smith and J.D. Winefordner, J. Anal. At. Spectom., 14, 19-26 (1999).

12) O.V. Borisov, X.L. Mao, and R.E. Russo, Spectrochimica Acta, 55B, 11, 1693-1704 (2000).

13). A.J.G. Mank, and P.R.D. Mason, J. Anal Atom. Spectrom., 14: (8) 1143-1153 (1999). 


\section{List of Figures}

Figure 1. Dependence of ablated mass on the amount of Teflon ${ }^{\circledR}(\star)$ and poly(ethylene glycol) ( 凶) binder at laser beam irradiance of $0.018 \mathrm{GW} \mathrm{cm}^{-2}$. Data are determined based on crater volume measurements using repetitive laser ablation with 1800 pulses on three randomly selected locations.

Figure 2. Time-profiles for ${ }^{138} \mathrm{Ce}$ (a) and ${ }^{115} \mathrm{In}$ (b) isotopes during repetitive laser ablation at irradiances of 0.006 (solid), 0.016 (dashed), and 0.21 (dotted) $\mathrm{GW} \mathrm{cm}{ }^{-2}$.

Figure 3. Time-profiles for ${ }^{115} \mathrm{In} /{ }^{138} \mathrm{Ce}$ isotopic ratio during repetitive laser ablation at irradiances of 0.006 (solid), 0.016 (dashed), and 0.21 (dotted) $\mathrm{GW} \mathrm{cm}^{-2}$ for a pellet with Teflon ${ }^{\circledR}$ binder (a). Dependence of ${ }^{115} \mathrm{In} /{ }^{138} \mathrm{Ce}$ isotopic ratio after $60 \mathrm{~s}$ of pre-ablation and $10 \mathrm{~s}$ integration time on laser beam irradiance for pellets with Teflon ${ }^{\circledR}(\mathbb{*})$ and poly(ethylene glycol) (困) as a binder (b).

Figure 4. Dependence of ${ }^{138} \mathrm{Ce}$ signal normalized to a laser beam area ( $\star$ ) and ${ }^{208} \mathrm{~Pb} /{ }^{138} \mathrm{Ce}$ isotopic ratio (凶) (a) and ${ }^{138} \mathrm{Ce}$ signal RSD (b) on laser beam irradiance during repetitive ablation with $60 \mathrm{~s}$ of pre-ablation and $10 \mathrm{~s}$ integration time.

Figure 5. Dependence of ${ }^{113} \mathrm{In}$ signal intensity on the amount of ablated mass over $30 \mathrm{~s}$ of repetitive pulsing on a single spot.

Figure 6. ICP-MS signal intensity for an internal standard $\left({ }^{115} \mathrm{In}\right)$ for pellets with different amounts of $\mathrm{CeO}_{2}$ during raster-mode ablation $(\square)$ and repetitive pulsing on a single spot $(\star)$ at laser beam irradiance of $0.1 \mathrm{GW} \mathrm{cm}^{-2}$.

Figure 7. Calibration plots for ${ }^{208} \mathrm{~Pb}$ from Teflon ${ }^{\circledR}$-binded pellets during single spot ablation without (a) and with internal standardization (c) and raster-mode ablation without internal standardization (b). 